\title{
COMPLICAÇÃO OU ERRO MÉDICO?
}

\section{COMPLICATIONS OR MALPRACTICE?}

\author{
Edmundo Machado Ferraz, TCBC \\ Chefe do Serviço Cirurgia Geral do HC-UFP
}

Quando um tratamento médico ou uma cirurgia realizada em um paciente não apresenta bons resultados é freqüente a dúvida seguida da indagação do paciente ou de sua família se o insucesso foi um mau resultado do procedimento ou decorrente de um erro médico.

O tratamento médico, particularmente o cirúrgico não é isento de risco. Qualquer cirurgia realizada em um paciente tem um componente de risco, inclusive a cirurgia estética que tem um agravante de ser realizada em pessoa normal, que não é portadora de doença.

O risco pode ser de mortalidade e/ou de morbidade, ou seja, complicações inerentes ao procedimento que podem ser classificadas em leves, moderadas ou graves quando importam em risco de vida do paciente. As complicações podem ainda ser consideradas como precoces ou tardias, independente de sua gravidade.

Consideram-se complicações imediatas as que ocorrem até 30 dias do tratamento cirúrgico, mesmo que o paciente esteja em sua residência, e as tardias após esse prazo.

O risco anestésico-cirúrgico deve ser discutido previamente com o paciente e seus familiares, recomendando-se que, em circunstâncias de maior risco, seja fornecido e assinado pelo paciente um Termo de Responsabilidade no qual ficam esclarecidos todos os riscos inerentes ao procedimento a que o mesmo será submetido. Recentemente, representantes do judiciário têm considerado que a ausência do Termo de Responsabilidade poderia ser imputada como negligência médica.

O risco será maior ou menor dependendo das características do tratamento se eletivo, ou de urgência (emergência) e dos fatores de risco do paciente, caracterizado por complicações ou doenças associadas de que o paciente seja portador.

Por exemplo, uma colecistectomia vídeolaparoscópica indicada de modo eletivo ou programada pelo diagnóstico de cálculo sintomático da vesícula biliar, em uma paciente com menos de 40 anos, sem doença associada, tem um risco de mortalidade inferior a $0,2 \%$ e um risco de morbidade inferior a 5\%, caracterizado por infecção do sitio cirúrgico, infecção respiratória, infecção urinária, litíase residual além de complicações respiratórias, cardiovasculares ou tromboembólicas.
Este mesmo procedimento, colecistectomia vídeolaparoscópica, praticado em caráter de urgência, em um paciente acima de 70 anos, diabético descompensado, hipertenso, com antecedentes de coronariopatia e dislipidemia, obeso, com doença pulmonar obstrutiva crônica, situação bastante freqüente nesta faixa etária em uma população cada vez maior de idosos, apresenta uma elevada taxa de risco de morbidade (complicações), 10 a $15 \%$ e mortalidade que pode atingir ou ultrapassar os 5\%. Este paciente operado em caráter de urgência ou mesmo eletivamente, com todos os procedimentos diagnósticos e terapêuticos realizados com prudência e técnica apropriada, pode ter um mau resultado, desenvolver complicação e falecer no decurso do tratamento. Isto constitui uma complicação e não um erro médico que necessitaria das figuras dos Códigos Civil e Penal Brasileiros: imperícia, imprudência ou negligência para que pudesse o resultado ser considerado como erro médico.

Por outro lado, esse mesmo paciente poderia ter sido operado por um profissional competente e cuidadoso em um Hospital que não dispusesse de uma Unidade de Terapia Intensiva preparada para receber esse paciente e ai teríamos inserida a figura da negligência, o que tornaria o ato médico passível de ser considerado como erro médico.

Contudo, se fosse o único hospital capaz de atender o paciente nas circunstâncias em que o paciente se apresentava e impossibilitado de ser transferido (presença de estado de choque séptico, por exemplo) para um hospital que dispusesse das condições ideais de tratamento, certamente que o paciente teria sido vitima de uma complicação e não de um erro médico.

Uma outra situação que poderia ocorrer e que, infelizmente ocorre em grande número de hospitais públicos brasileiros é a seguinte: a Unidade de Terapia Intensiva apresenta-se superlotada e o paciente operado não pode ser admitido na mesma, realizando o seu período pós-operatório imediato em uma unidade inadequada ao seu tratamento. Esta é uma situação freqüente e que acreditamos que cabe ao Ministério Público examinar essas ocorrências e estabelecer o nível e grau de responsabilidade do profissional que realizou o procedimento e do órgão gestor da Instituição em que ocorreu a complicação ou óbito por ausência de vaga no local adequado do tratamento. Esta não é uma questão fácil. 
Uma outra situação é a falta de seguimento de protocolo determinados por nossa legislação para procedimentos de alta complexidade na unidade hospitalar.

Qualquer quebra das recomendações da Comissão de Controle de Infecção Hospitalar, obrigatória em nossos hospitais, caracteriza negligência ou imprudência. Não necessariamente um paciente operado que desenvolve uma infecção adquirida no Hospital complica por culpa da instituição.

Tomemos o exemplo citado do paciente de 70 anos com múltiplas complicações. Operado e após 72 horas de admissão na UTI esse paciente tem uma alta probabilidade de desenvolver uma infecção adquirida na Unidade de Terapia Intensiva em conseqüência à diminuição dos seus mecanismos de defesa por conta das suas doenças. Esse tipo de paciente desenvolve freqüentemente pneumonia, particularmente se estiver em respirador, não podendo ser imputada essa in- fecção como de responsabilidade do Hospital. Por outro lado, se o Hospital não dispõe de profissional capacitado e antibióticos adequados para tratar essa complicação, certamente que o Ministério Público pode caracterizar negligência ou imprudência do gestor da instituição neste caso específico.

Dentre as figuras dos Códigos Civil e Penal, a imperícia teoricamente é a mais fácil de ser imputada, sendo muito importante considerar a experiência e os resultados prévios do cirurgião no tipo de procedimento analisado. A opinião dos pares nem sempre pode ser separada do corporativismo existente na classe médica (e em todas as outras), o que pode confundir o julgamento quando encaminhado ao Ministério Público ou ao Judiciário.

Finalizando, a complicação é um evento inerente aos procedimentos médicos e deve ser cuidadosamente separada dos procedimentos em que ocorreram negligência, imperícia ou imprudência que caracterizam o erro médico. 